\title{
Declaração de Belém: o recrutamento e a retenção de profissionais de saúde em áreas rurais e remotas
}

The Belém declaration: recruitment and retention of health professionals in rural and remote areas

Declaración de Belém: reclutamiento y retención de profesionales de salud en areas rurales y remotas

Leonardo Vieira Targa. Universidade de Caxias do Sul (UCS). Caxias do Sul, RS, Brasil. targalv@gmail.com (Autor correspondente) André Luiz da Silva. Pontifícia Universidade Católica do Rio Grande do Sul (PUC-RS). Porto Alegre, RS, Brasil. barmitzvar@yahoo.com.br Dijon Hosana Souza Silva. Secretaria Municipal de Saúde de Floresta Azul. Floresta Azul, BA, Brasil. dijonhosana@hotmail.com Enrique Falceto de Barros. Secretaria Municipal de Saúde de Santa Maria do Herval. Santa Maria do Herval, RS, Brasil. enriquefbarros@gmail.com Fábio Duarte Schwalm. Universidade de Caxias do Sul (UCS). Caxias do Sul, RS, Brasil. fschwalm@gmail.com

Leonardo Cançado Monteiro Savassi. Universidade Federal de Ouro Preto (UFOP). Ouro Preto, MG, Brasil. leosavassi@gmail.com

Monica Correia Lima. Prefeitura Municipal de Cajati. Cajati, SP, Brasil. monicalima@usp.br

Otávio Silva. Prefeitura Municipal de Alcântara. Alcântara, MA, Brasil. otaviocsilva@gmail.com

Ricardo César Garcia Amaral Filho. Universidade do Estado do Amazonas (UEA). Manaus, AM, Brasil. amaral.mfc@gmail.com

Rodrigo Silveira. Universidade Federal do Acre (UFA).Rio Branco, AC, Brasil. ropsilveira@gmail.com

Magda Almeida. Universidade de Fortaleza (UNIFOR). Fortaleza, CE, Brasil. magnhets@gmail.com

Nilson Massakazu Ando. Secretaria Municipal de Saúde de Manaus (SEMSA). Manaus, AM, Brasil. nilsonando@yahoo.com

\section{Resumo dos debates orientados pelas evidências científicas e experiências dos membros do Grupo de Trabalho de Medicina Rural da SBMFC}

Tendo se reunido em Belém-PA, em maio de 2013, durante o 12 Congresso Brasileiro de Medicina de Família e Comunidade, o Grupo de Trabalho de Medicina Rural da Sociedade Brasileira de Medicina de Família e Comunidade (SBMFC), baseado em estudos prévios das evidências publicadas nacional e internacionalmente e na própria experiência como médicos rurais e estudiosos do tema, após debate e consenso, considerando que:

- O Brasil é um país continental e com enorme variedade locorregional;

- O conceito de ruralidade aqui utilizado será o da Declaração de Brasília; ${ }^{1}$

- A saúde das populaçôes rurais e remotas apresenta características específicas, que a difere da saúde das populaçóes de grandes áreas urbanas e, em grande parte, os indicadores de saúde daquelas populações são inferiores às últimas; ${ }^{2-5}$

- As populações de áreas rurais e remotas têm a saúde como direito assegurado constitucionalmente, tanto quanto qualquer outra população; ${ }^{6}$

- O Sistema Único de Saúde (SUS) brasileiro tem como pressupostos a atenção universal, integral e com equidade para os cidadáos brasileiros, ${ }^{6}$ entretanto não estão atualmente assegurados o acesso, a longitudinalidade, a integralidade, a coordenação do cuidado, nem a qualidade das açóes de saúde para as populaçóes rurais; ${ }^{3}$

Como citar: Targa LV, Silva AL, Silva DHS, Barros EF, Schwalm FD, Savassi LCM et al. Declaração de

Fonte de financiamento: SBMFC.

Conflito de interesses: declaram não haver. Recebido em: 26/09/2013 Aprovado em: 04/10/2013 
- Existe em todo o país escassez de recursos humanos para a saúde e este fato não pode ser explicado, exclusivamente, pela falta de profissionais, mas, preferentemente, pela má distribuição destes. ${ }^{3,7}$

\section{O GT de Medicina Rural da SBMFC declara:}

- É essencial que o governo brasileiro, assegurando adequada participaçáo social, assuma a responsabilidade da criaçáo e sustentação de políticas públicas, direcionadas para a iniquidade da situação de saúde das populaçóes rurais.

- Estas políticas devem ser, preferencialmente, adequadas regionalmente e, se necessário, localmente.

- Múltiplas estratégias devem ser adotadas simultaneamente, ao invés de escolherem-se estratégias isoladas, sendo que uma política adequada de recrutamento e retenção de recursos humanos, que englobe múltiplas estratégias, deve fazer parte das políticas anteriormente citadas, embora não sejam suficientes. ${ }^{8}$

- As políticas de recrutamento e retenção de recursos humanos em saúde não podem ser construídas separadamente das políticas de aprimoramento do sistema de saúde e da gestão, e deveriam estar relacionadas com maior orientação do sistema de saúde para a Atenção Primária à Saúde (APS). ${ }^{?}$

- Deve-se ter em mente que a prática do cuidado à saúde em áreas rurais não se constitui em cenários diferentes, da simples aplicação de evidências científicas descontextualizadas e portanto, as políticas voltadas para esta área não devem estar em desarmonia com as políticas de formação e treinamento.

- Políticas de formação de profissionais de saúde, tanto em nível de graduação como de pós-graduação, devem ser redirecionadas para a obtenção de profissionais com perfil generalista. O Médico de Família e Comunidade (MFC), em nosso país, deve ser o profissional de referência para a prática em áreas rurais e remotas, pois este é o perfil profissional que internacionalmente obtém melhores resultados nestas condiçóes. ${ }^{9} \mathrm{O}$ mesmo perfil deveria ser buscado nas demais profissôes da saúde, preferencialmente, e o trabalho em equipe deve ser estimulado. A formação destes profissionais deve ser direcionada para as demandas das comunidades locais.

- Estratégias de pré-seleção de estudantes nas universidades para perfis voltados para a APS e para a Medicina de Família e Comunidade são internacionalmente relacionadas a melhores desfechos para esta necessidade e deveriam ser criadas juntamente com: (a) políticas de pré-seleção de estudantes de áreas rurais e remotas, carentes de profissionais de saúde; e (b) descentralização progressiva dos cursos da área da saúde.

- Estratégias que aumentam o recrutamento temporariamente, mas não fixam o profissional nas áreas rurais, como o serviço temporário obrigatório ou voluntário (assim como as que premiam o profissional ao terminar o prazo de serviço ou ao retornar para a cidade), não deveriam ser a primeira opção, tampouco prioritárias, visto que têm potencial de prejudicar a qualidade, a longitudinalidade e a integralidade do cuidado, além de, indiretamente, desestimular as melhorias dos sistemas de saúde locais e a busca de um perfil profissional adequado. Estas podem, entretanto, ser soluçôes opcionais quando outras alternativas se mostrarem infrutíferas, devendo ser reavaliadas periodicamente quanto à sua necessidade, devido ao seu caráter de soluçáo a curto prazo. Ao se optar por premiaçáo após o serviço rural, deve-se priorizar o estímulo às especialidades deficitárias e generalistas.

- Estratégias de valorizaçáo do profissional rural devem ser adotadas, por exemplo, premiaçóes por longitudinalidade, o escopo mais amplo de habilidades e procedimentos, dificuldade de acesso.

- Estratégias de diminuição do isolamento do profissional, como o acesso adequado às tecnologias de informação, a existência de internet de boa qualidade, redes bem estruturadas de referência e consultoria presenciais e/ou a distância e o estímulo governamental às associações de profissionais rurais, conferências e publicaçóes.

- Estratégias de facilitaçáo de inserçáo acadêmica, como o mapeamento e apoio aos programas curriculares que incorporam estágios ou disciplinas de saúde rural, apoio à inserção em projetos de pesquisa e capacitação para tal, apoio à descentralização de cursos da área da saúde.

- Estratégias de migraçáo de profissionais estrangeiros deveriam ser encaradas como soluçóes emergenciais, de curto prazo, somente após outras opçóes terem sido esgotadas e sempre respeitando as regras nacionais respectivas. 
- Estratégias de apoio à qualidade de vida do profissional e sua família, visto que são fatores importantes diagnosticados para a não fixação em muitas áreas rurais. Exemplos clássicos são: o auxílio à moradia, obtenção de emprego para cônjuge, transporte, educação dos filhos e remuneração.

\section{O GT de Medicina Rural define que:}

De forma resumida, sem o fortalecimento do SUS, o aprofundamento de seu direcionamento para APS e a melhoria na gestão, com direcionamento adequado de recursos, não será possível uma solução duradoura e adequada para o problema da falta de recursos humanos em saúde.

Estratégias múltiplas e regionalizadas deveriam fazer parte de uma política mais ampla de recursos humanos, que necessariamente estivesse conectada com transformaçóes na formação de profissionais para um perfil preferencialmente generalista e qualificado. Soluções de curto prazo, que recrutem e não fixem profissionais nas áreas rurais só podem ser tomadas como opção complementar não devendo ser prioritárias.

\section{Referências}

1. Ando NM, Targa LV, Almeida A, Silva DHS, Barros EF, Schwalm FD, et al. Declaração de Brasília: o conceito de rural e o cuidado à saúde. Rev Bras Med Fam Comunidade. 2011 Abr-Jun; 6(19): 142-4. http://dx.doi.org/10.5712/rbmfc6(19)390

2. Brasil. Uma Análise da Situação da Saúde. Brasília: Ministério da Saúde; 2004.

3. Targa LV. Saúde Rural e a Medicina de Família e Comunidade. In: Gusso G, Ceratti JML. Tratado de Medicina de Família e Comunidade. Porto Alegre: Artmed; 2012.

4. Instituto Brasileiro de Geografia e Estatística (IBGE). Diretoria de Pesquisas. Coordenação de Trabalho e Rendimento. Pesquisa Nacional por Amostra de Domicílios: Um panorama da saúde no Brasil. Acesso e utilização de serviços, condições de saúde e fatores de risco e proteção à saúde, 2008. Rio de Janeiro: IBGE; 2010.

5. Instituto Brasileiro de Geografia e Estatística (IBGE). Departamento da População e Indicadores Sociais. Evolução e perspectivas da mortalidade infantil no Brasil. Rio de Janeiro: IBGE; 1999.

6. Brasil. Constituição da República Federativa do Brasil de 1988. Disponível em: http://www.planalto.gov.br/ccivil_03/constituicao/constituicao.htm

7. Conselho Federal de Medicina. Jornal do Conselho Federal de Medicina, 2010. Resumo. Disponível em: http://portal.cfm.org.br/index.php?option=com_ content\&view=article\&id=9777\&catid=3: portal.

8. Organização Mundial de Saúde - OMS. Increasing access to health workers in remote and rural areas through improved retention. Genebra; 2010.

9. Starfield B. Atenção Primária: Equilíbrio entre necessidades de saúde, serviços e tecnologia. Brasília: UNESCO, Ministério de Saúde; 2002. 